\title{
Twin Reversed Arterial Perfusion Sequence Malformation
}

National Cancer Institute

\section{Source}

National Cancer Institute. Twin Reversed Arterial Perfusion Sequence Malformation. NCI

Thesaurus. Code C111656.

A severe form of twin-twin transfusion syndrome that occurs in monochorionic pregnancies. The normal twin (pump twin) supplies the blood flow to its sibling that lacks heart or brain or both (acardiac/acephalic twin). Untreated, it may lead to the demise of the pump twin in some cases. 